\title{
Primary care physicians' perceptions of the role of alternative payment models in recruitment and retention in rural Alberta: a qualitative study
}

\author{
Yewande Ogundeji PhD, Fiona Clement PhD, Darryn Wellstead PhD, Brenlea Farkas MSc, \\ Braden Manns MD MSc
}

\section{Abstract}

Background: Despite well-documented challenges in recruiting physicians to rural practice, few Canadian studies have described the role physician payment models may play in attracting and retaining physicians to rural practice. This study examined the perspectives of rural primary care physicians on the factors that attract and retain physicians in rural locations, including the role that alternative payment models (APMs) might play.

Methods: This was a qualitative study involving in-depth, open-ended interviews with rural primary care physicians practising under feefor-service (FFS) models and APMs in Alberta, Canada. Participants were recruited from the Rural Health Professions Action Plan member list (consisting of physicians practising in rural or remote locations in Alberta) and the College of Physicians and Surgeons of Alberta online database. Interviews were conducted April to June 2020, and data were analyzed using a thematic framework approach.

Results: Fourteen physicians were interviewed. There were 5 themes identified: factors that attract physicians to rural practice, barriers and challenges associated with rural practice, the potential role of APMs in recruitment and retention, factors that physicians consider in deciding to change payment models, and physician perceptions of APMs compared with FFS models. Participants expressed that APMs may have some role to play in retaining rural physicians but identified professional challenges, and family-related and personal factors as key determinants. Most FFS physicians indicated that they were interested in exploring APMs provided specific concerns were addressed (e.g., clear and adequately compensated APM contracts, and physician involvement in the development of APMs).

Interpretation: Primary care physicians practising in rural regions in Alberta view payment models as one consideration among many in their decision to pursue rural practice. Alternative payment model contracts designed with the input of physicians may have a role to play in attracting and retaining physicians to rural practice.

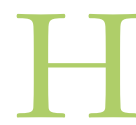
ealth disparities between rural and urban regions are well documented in Canada and across the globe. ${ }^{1,2}$ Despite the need for strong primary care systems in rural areas, a relatively low proportion of physicians choose to practise in rural regions. In Canada, rural areas account for about a third of the population, but only about $15 \%$ of physicians, and physician recruitment and retention in rural locations remains an ongoing challenge. ${ }^{1}$

Research exploring factors influencing recruitment and retention has tended to highlight 4 key themes: personal (e.g., rural background), community (e.g., social and recreational activities), education (e.g., rural placement during training) and policy (e.g., financial incentives). ${ }^{3,4}$ Within the literature, studies consistently note that a combination of these factors seems to be a strong predictor of rural recruitment and retention. ${ }^{3-5}$ Noticeably missing from this literature is attention to the role that alternative payment (non-fee-for-service [FFS]) models could play in recruiting and retaining physicians to rural regions.

In Canada, traditional FFS is the predominant payment model for primary care physicians. In Alberta, policy reform over the last 2 decades has led to the development and implementation of alternative payment models (APMs; including blended capitation and salary-based models) aimed at improving recruitment and retention, access, quality and fiscal sustainability. ${ }^{6}$ Currently, a relatively small proportion $(17 \%)$ of Alberta's physicians are paid through APMs, ${ }^{7}$ whereas in other provinces more than $40 \%$ of physicians are compensated (partially or fully) through APMs. ${ }^{8}$

To date, research on APMs has primarily focused on exploring the potential impact of APMs on team-based care in primary care settings, and access and quality of care for patients with chronic diseases. ${ }^{9-11}$ Given the increasing policy focus on recruitment and retention of rural physicians, in this

Competing interests: None declared.

This article has been peer reviewed.

Correspondence to: Yewande Ogundeji, yewande.ogundeji@ucalgary.ca, ykogundeji@gmail.com; Braden Manns, Braden.Manns@ albertahealthservices.ca

CMAJ Open 2021. DOI:10.9778/cmajo.20200202 
study, we sought rural physicians' perspectives on the factors that attract and retain physicians in rural locations, including the role that APMs might play.

\section{Methods}

We conducted in-depth, semistructured qualitative interviews with physicians currently practising in rural communities in Alberta, Canada, who were paid either by an FFS model or APM. Interviews were conducted from April to June 2020.

\section{Study context}

At the time of the study, lockdown restrictions resulting from the COVID-19 pandemic had been put in place in Alberta. This had an impact on demand for and availability of health services within the province, with limited in-person consultations during the period. In addition, there was growing tension between the government and physicians due to the unilateral cancellation of the contract between the government and the Alberta Medical Association (including a reduction in compensation) when negotiations between the 2 groups were unsuccessful.

\section{Sampling and recruitment}

We used a purposive sampling method to recruit primary care physicians practising in rural and remote areas. This approach ensured we captured perspectives from male and female physicians, and physicians paid through FFS models and APMs. ${ }^{12}$ Potential participants were identified through an email facilitated by the Rural Health Professions Action Plan. This group supports practising rural physicians and serves as a resource for rural community health workforce attraction and retention. The Rural Health Professions Action Plan shared an information sheet detailing the study goals and protocol with members (rural physicians) on its mailing list. Using the College of Physicians and Surgeons of Alberta website, the principal investigator also emailed physicians who practise in rural or remote towns offering APMs. Interested participants were encouraged to contact members of the study team to arrange a time and date for the telephone interview.

\section{Data collection}

The interview guide (Appendix 1, available at www.cmajopen. $\mathrm{ca} /$ content/9/3/E788/supp1/DC1) included semistructured, open-ended questions that were informed by existing literature and developed iteratively by the research team. We conducted a broad search of rural physician recruitment and retention literature over the past 10 years in 5 databases: MEDLINE, Cochrane Central Register of Controlled Trials (CENTRAL), Embase, Cochrane Database of Systematic Reviews and EconLit. Terms aimed to capture the population of interest such as "physician," "general practitioner" and "doctor" were combined with intervention and outcome terms such as "recruitment," "retention," "incentive" and "compensation" using the Boolean operator "and." Additional terms were used to limit the results to rural and remote studies. On the basis of identified relevant literature, ${ }^{1,3,4}$ we developed an initial list of relevant interview questions.
The guide was piloted with 3 physicians practising in rural areas and further refined. The questions asked physicians to describe demographic characteristics (years in rural practice, gender, type of payment model and country of training), their clinical practice and background, factors that influenced their choice for rural practice (including the role of payment models), their interest in switching payment models, and perceptions on how payment models influence practice patterns. While the guide was focused on the specific questions underlining our research objectives, we provided opportunities for participants to expand on their views, and frequently explored their perspectives using probes and other interviewing prompts. In addition, because of the potential bias or influence of current circumstances (e.g., the COVID-19 pandemic and tension between the government and physicians) on participants' responses, the interviewers further probed respondents about views and perceptions under previous circumstances.

Data saturation (when no new ideas or patterns emerged) was reached after 8 interviews; however, we continued interviewing past saturation to validate and further enhance the development of themes and assess the consistency of results in various types of physicians. ${ }^{13}$ The interviews and analysis were completed by 2 experienced female postdoctoral qualitative researchers (D.W. and Y.O.) who had no prior relationship with the respondents. The interviewers took extensive notes during and after the interviews and engaged in memoing and peer-debriefing to formulate initial themes and to enhance reflexivity and study credibility..$^{14,15}$ All interviews were conducted via telephone and digitally audiorecorded, transcribed and anonymized.

\section{Data analysis}

Interview transcripts were analyzed using the framework approach by Ritchie and Spencer, ${ }^{16}$ facilitated through NVivo Version 12. The framework approach analyzes data in 5 steps: familiarization, identifying a thematic framework, indexing, charting, and mapping and interpretation. This allows for a transparent audit trail to show how results have been derived from the data, which enhances the rigour of the analytical processes. ${ }^{17}$ The researchers began by reading the transcripts independently to familiarize themselves with the data and to identify key themes (thematic framework) and codes, and then compared their notes. Through this comparative process, the researchers refined initial themes and identified emergent themes to develop a codebook to group codes into themes. The researchers met regularly to refine the codebook, compare coding decisions, and ensure that consensus was achieved on coding disagreements to enhance credibility. ${ }^{14}$ Once coding was complete, data were imputed into a framework matrix to identify patterns and connections within and between themes and across participants. The researchers met to review and reach consensus on emerging themes and key findings from the analysis. To further enhance credibility, we also provided participants with a summary of our findings and opportunity for feedback.

\section{Ethics approval}

The study was approved by the Conjoint Health Research Ethics Board at the University of Calgary. 


\section{Resullts}

We interviewed 14 primary care physicians (8 FFS, 6 APM). Nine physicians $(64 \%)$ were male and $5(36 \%)$ were female. Six participants $(43 \%)$ were early-career physicians $(\leq 10 \mathrm{yr}$ in practice), and $8(57 \%)$ were mid- to late-career physicians. Eight $(57 \%)$ had attended medical school in Canada, and 6 (43\%) had attended medical school internationally (Table 1). Interviews lasted an average of 50 minutes, ranging from 25 minutes to 1 hour and 29 minutes. No participants withdrew from the study.

\section{Themes}

The study identified 5 major themes: factors attracting physicians to rural practice, barriers and challenges associated with rural practice, the potential role of APMs in recruitment and retention, factors that physicians consider in deciding to change payment models (i.e., factors that influence rural physicians' preference for APMs), and physician perceptions of APMs compared with FFS models. A summary of our findings, including the thematic framework and codes, is presented in Table 2 .

\section{Factors attracting physicians to rural practice}

Most physicians interviewed for this study viewed rural medicine as a "package deal," weighing several factors into their final decision to practise rurally. This package included the following: community factors, such as quality of life, attraction to the rural lifestyle and the sense of valued contribution to the community; monetary and nonmonetary incentives, such as relocation support; personal factors, such as previous rural experience and family-related factors; and professional factors, including autonomy in practice, the broad scope of practice and strong patient-physician relationships (Box 1). Of these factors, physicians emphasized the broad scope of practice and the attractiveness of rural living as key drivers motivating them to

\begin{tabular}{|c|c|c|}
\hline Characteristic & $\begin{array}{c}\text { Salary-based } \\
\text { model } \\
n=6\end{array}$ & $\begin{array}{l}\text { FFS } \\
n=8\end{array}$ \\
\hline \multicolumn{3}{|l|}{ Gender } \\
\hline Female & 3 & 2 \\
\hline Male & 3 & 6 \\
\hline \multicolumn{3}{|l|}{ Career stage } \\
\hline $\begin{array}{l}\text { Early career } \\
\text { (up to } 10 \mathrm{yr} \text { in practice) }\end{array}$ & 5 & 4 \\
\hline $\begin{array}{l}\text { Mid-late career } \\
(>10 \text { yr in practice) }\end{array}$ & 1 & 4 \\
\hline \multicolumn{3}{|l|}{ Medical school training } \\
\hline Foreign & 1 & 5 \\
\hline Canada & 5 & 3 \\
\hline
\end{tabular}

work in rural locations. Thus, both professional fulfillment and lifestyle considerations weighed into the decision.

\section{Barriers and challenges associated with rural practice}

Participants highlighted several challenges associated with rural practice that may affect retention. The most commonly cited challenges were professional, relating to workload, on-call burden, keeping up the breadth and depth of skills required for rural practice, and health care system challenges, including policy changes (Box 2). For instance, participants noted challenges relating to inadequate access to specialists and outdated equipment, which they felt affected patient care. In particular, physicians emphasized the high workload and on-call burden.

Some participants also reported that recent changes (in 2019/20) to the billing code structure for rural FFS physicians by the Alberta government had led to distrust. Physicians who indicated they were frustrated or dissatisfied with their practice of rural medicine explained that they were not looking to leave rural practice but, rather, move to other locations where they felt they would be better supported by the government.

\section{The potential role of APMs in recruitment and retention}

Overall, physicians felt that payment models have some role to play in attracting and retaining rural physicians (Box 3). Those on APMs perceived that certain attributes of an APM might be attractive for physicians considering making the move to rural practice (e.g., an APM might facilitate a collaborative, team-based care model). For instance, they described how collaboration with allied health professionals could help distribute the workload and triage patient care. Patients with minor issues could receive care from nurse practitioners or through telephone follow-ups, reserving in-person physician appointments for patients with more serious issues. Conversely, a few FFS physicians expressed that they would not be interested in APMs, as they were concerned that APM contracts might be vague or might be cancelled without consultation. In these cases, a change in payment model from FFS to an APM was likely to negatively influence the decision to remain in rural practice in Alberta.

\section{Factors that physicians consider in decisions around payment model changes}

Overall, most physicians were open to considering other payment models. Of note, whereas APM physicians were more reluctant to consider FFS, some FFS physicians were more open to APMs, provided that the government addressed specific concerns (Box 4). For FFS physicians who were willing to consider APMs, they emphasized difficulties in APM administration and the importance of developing "fair" and clear contracts that included adequate compensation for the amount of work.

A few physicians who were not willing to explore APMs indicated their reason was mainly their distrust of government. Specifically, physicians indicated that the recent changes by the Alberta government made them hesitant to consider new contracts over fear of sudden changes without 
Table 2: Summary of themes and categories

\begin{tabular}{|c|c|c|}
\hline Themes & Subthemes & Categories* \\
\hline \multirow[t]{4}{*}{$\begin{array}{l}\text { Factors attracting physicians to } \\
\text { rural areas }\end{array}$} & Community factors & $\begin{array}{l}\text { Attracted to rural lifestyle; quality of life; valued } \\
\text { contribution or work in the community }\end{array}$ \\
\hline & Financial incentives & Monetary and nonmonetary incentives \\
\hline & Personal and family-related factors & $\begin{array}{l}\text { Access to child care; retirement plan; previous personal } \\
\text { rural experience; spousal factors }\end{array}$ \\
\hline & Professional factors (motivators) & $\begin{array}{l}\text { Autonomy or independence; patient-physician } \\
\text { relationships; variety in the scope of practice }\end{array}$ \\
\hline \multirow{4}{*}{$\begin{array}{l}\text { Barriers and challenges } \\
\text { associated with rural or remote } \\
\text { practice }\end{array}$} & Challenges related to patient care & $\begin{array}{l}\text { Complex patient panel; limited access to specialists; } \\
\text { outdated or old equipment or facilities }\end{array}$ \\
\hline & Community challenges & $\begin{array}{l}\text { Cold or severe climate; cultural or ideological differences; } \\
\text { community pressures }\end{array}$ \\
\hline & Family-related and personal factors & $\begin{array}{l}\text { Season of life needs; spousal factors; work-life } \\
\text { balance }\end{array}$ \\
\hline & Practice and professional challenges & $\begin{array}{l}\text { Keeping up with clinical knowledge; high on-call } \\
\text { burden; travel- or professional-related barriers }\end{array}$ \\
\hline $\begin{array}{l}\text { Potential role of APMs in } \\
\text { recruitment and retention }\end{array}$ & $\begin{array}{l}\text { Ability to share workload with allied health } \\
\text { care workers on an APM; APM could } \\
\text { attract new physicians }\end{array}$ & \\
\hline \multirow{3}{*}{$\begin{array}{l}\text { Factors that physicians } \\
\text { consider in decisions around } \\
\text { payment model changes } \\
\text { (factors that influence physician } \\
\text { preferences for APMs) }\end{array}$} & Contract concerns & $\begin{array}{l}\text { Fair contracts; potential to earn less; fear of loss of } \\
\text { autonomy and flexibility; feasibility of one payment model } \\
\text { for all types of clinical work; involvement of physicians } \\
\text { in payment model design }\end{array}$ \\
\hline & Implementation concerns & $\begin{array}{l}\text { Difficulty in administration; financial losses associated } \\
\text { with changing payment models }\end{array}$ \\
\hline & Peculiarities of rural practice & Population fluctuations; travel costs \\
\hline \multirow[t]{3}{*}{$\begin{array}{l}\text { Physician perspectives on } \\
\text { payment models }\end{array}$} & $\begin{array}{l}\text { Impact on patient care and physician } \\
\text { practice }\end{array}$ & $\begin{array}{l}\text { APM impacts: enables holistic patient care; more time } \\
\text { with patients; potential loss of physician autonomy } \\
\text { FFS impacts: improved patient access; tendency to } \\
\text { have more follow-ups; tendency to spend shorter } \\
\text { periods with patients }\end{array}$ \\
\hline & Remuneration impacts & $\begin{array}{l}\text { APM: income security; paid vacation time; potential } \\
\text { cost savings } \\
\text { FFS: under pressure for income to keep practice } \\
\text { running; income less stable }\end{array}$ \\
\hline & Potential for perverse incentives & $\begin{array}{l}\text { APM impacts: loss of drive to innovate, improve or } \\
\text { see patients; "free rider problem" } \\
\text { FFS impacts: might incent some physicians to see too } \\
\text { many patients }\end{array}$ \\
\hline
\end{tabular}

consultation. However, participants felt that concerns about potential problems with the implementation and administration of APMs in rural regions might be mitigated if physicians were involved in the contract design. Physicians further emphasized the need for rural doctors to be involved in the development of APM contracts, not only to feel that their voices and experiences were valued, but also to offer evidence related to physicians' experiences and patient benefits. Finally, physicians expressed worries that under an APM, physicians might be more restricted in terms of hours, schedule and workload, among other factors. As such, physicians emphasized that APMs should provide space for flexibility and autonomy in how physicians practise.

\section{Physician perceptions of APMs compared with FFS}

In comparing physicians' perceptions about FFS models and APMs, 3 key domains emerged relating to impacts on patient care, practice and remuneration, and concerns about perverse incentives that may have negative unintended consequences for patient care (Box 5).

Overall, participants believed that FFS incentivizes doctors to see more patients and spend less time with each patient. They identified positive and negative implications for patient care, including increasing access and potentially lowering care quality (e.g., in patients with complex conditions who may require longer consultations). Physicians also noted that certain attributes of APMs may improve patient care. For example, 
Box 1: Quotes illustrating "Factors attracting physicians to rural practice"

- $\quad$ "It's about different activities. We go biking. We interact a lot with the community. My children are still little, so my neighbour is usually the one who's watching them when I have extra shifts if my husband is busy with work. So, all these factors made us love staying [here]." (001-APM physician)

- II wouldn't have been able to come here without the rural program. Yeah, they sponsored my anesthesia assessment, and I got a stipend throughout that." (003FFS physician)

- $\quad$ "I come from a really small town. I really loved where I grew up. I recognize that there were some serious gaps in clinical care as I was growing up, and certainly wanted to mitigate some of that when I got out of med school." (006-APM physician)

- $\quad$ "In a rural centre, you just having a broader scope of practice being able to work in different environments and different types of medicine." (002-FFS physician)

Note: $\mathrm{APM}=$ alternative payment model, FFS = fee-for-service.

\section{Box 2: Quotes illustrating "Barriers and challenges} associated with rural practice"

- $\quad$ "The other big thing is access for our patients to diagnostic tests. So, I can't get an echocardiogram here or a stress test here. I'm limited; I can get some kinds of ultrasound. ... So those are probably the major things." (005-APM physician)

- "The intensity of the work, the hours, the inability to switch off, you always have kind of a duty of care when needed within your community, right now for me, the biggest challenges." (002-FFS physician)

- "Most physicians that I see that move and that's once again immigrants like myself, move because they believe there's better schooling to bigger cities or private school." (007-FFS physician)

- It's absolutely relentless is what I would say. So, like you are never off duty. So, my phone is on 24 hours when l'm not on-call because you may need to be called in to help with a patient. So, it's really difficult. You don't just do your day's work and walk away. Like even on your days off you are checking on your patients. You are checking on your laboratories. You are helping colleagues. So, I think it's very difficult in a rural or remote practice to really be switched off." (002-FFS physician)

- "It's the political environment that would drive me away, not the work and not even the payment system." (013-FFS physician)

Note: $\mathrm{APM}=$ alternative payment model, $\mathrm{FFS}=$ fee-for-service.

because of the flexibility afforded through APMs, many physicians indicated that such models would reduce pressure to see a high volume of patients, and would enable physicians to spend more time with patients and structure their practice according to the needs of the community or their patient panel. Several physicians also described how APMs can facilitate team-based care and innovative methods of delivering health care, including collaboration with allied health professionals.

On remuneration impacts, there was a general sense that FFS models provided greater earning potential than APMs.
Box 3: Quotes illustrating "The potential role of alternative payment models in recruitment and retention"

- $\quad$ "I think if [an APM contract] was attractive it would make it easier to recruit to this area. So, I think like having an extra person to share the workload would reduce my workload, so that in itself would certainly be helpful." (002-APM physician)

- $\quad$ "[Our APM] helped to attract people to us, physicians. So that's been good because we have enough people right now to share call. They've told us that that's part of the reason they've come is the payment model. ... Just not having to be on the fee-for-service treadmill. Like not being pressured to see $\mathrm{x}$-number of patients a day." (004-APM physician)

- $\quad$ "I think it [the APM] would actually go a long way to improving the recruitment in the long run. I definitely think the newer generation of docs would work better in alternate payment models than in fee-for-service. Fee-for-service is really about being on a hamster wheel and driving volume and the new generation of docs are not interested in that whatsoever." (013-FFS physician)

Note: $A P M=$ alternative payment model, FFS = fee-for-service
Box 4: Quotes illustrating "Factors that physicians consider in decisions around payment model changes"

- $\quad$ "I know one of the current issues and concerns that a lot of physicians have is of the contract is actually quite vague and people are concerned that going into a varied contract you actually lose a lot of autonomy, and in a fee-for-service model it's very clear and you are kind of in control, whereas in an APM you are kind of giving over that control and you have this obligation to provide all of this care, but it's the goal posts can be moved at any point. So, I think that's one of the current concerns regarding it." (003-FFS physician)

- "I actually looked into it last year, so when the AMA were talking about that I contacted their team to see, get more information on it and see if it would be applicable to our practice, and at the time my colleagues were not interested in that model, so I didn't go any further." (002-FFS physician)

- $\quad$ "I think number one factor is the number of hours that you have to work, and the load, because as I mentioned earlier if I'm practising in a busier place than $<$ town $>$ then I would definitely would prefer a fee-for-service instead of working 24 hours and seeing only a small load of patients." (001APM physician)

- "I would want something that was very simple, and I would want it to feel fair to me. ... I would want something that feels fair and that doesn't require a lot of manipulation on my part." (011-APM physician)

- So, if the system suddenly changes autocratically without doctors feeling like they've been part of the process, and often especially if changes are put in by lawyers and politicians and accountants that do not understand. ... They have never done a 24-hour ER call in their life. They don't know what it's like. On paper it can look manageable, [but] they've never sat with a dying patient in, you know, managing multiple emergencies, whatever. ... And rural care has. [It] is experientially very unique and so I think doctors need to be part of the process and feel like they are part of the process." (003-FFS physician)

Note: $\mathrm{AMA}=$ Alberta Medical Association, $\mathrm{APM}=$ alternative payment model $\mathrm{ER}=$ emergency room, FFS = fee-for-service. 
Box 5: Quotes illustrating "Physician perceptions of APMs compared with FFS"

- $\quad$ "So, in an ARP, we are able to hire a huge team of allied health professionals. So, for example, we hire nurses and nurse practitioners within our clinic, and they help us to manage patient care within their scope, and it doesn't require that a physician see that patient each time. ... It also allows us [physicians] more time to spend on the more complex patients.... We are flexible to [do] refills over the phone and not require patients to come in for things that are not valueadded for their care. I think overall it works well for patients and providers." (008-APM physician)

- "I know that some of my colleagues make way more money in a fee-for-service environment. They see way more patients and they make way more than I would in a day of clinic work." (006-APM physician)

- $\quad$ "It [FFS] constrains in the sense that you do feel like under pressure to see a certain number of patients per day to make sure that your income is secure and you know, sometimes you would like to spend longer with less patients [than] what fee-for-service would allow." (002-FFS physician)

- "The one thing that's nice about being on the fee-for-service is I can sort of hustle if I want to. I can take more shifts. I can see more patients. I'm kind of the guy right now if you have a patient in the hospital you are not getting along with or someone that's been dumped by every other doctor in town, I'm the one that takes them on. I'm willing to take on that work." (005-FFS physician)

- $\quad$ "So you know, they start how many shifts, how much you will make and in our APM our payment model we also build in holiday time so you are paid during your holiday time and that's factored into that daily rate. It also simplifies things financially and that you don't worry about your overhead it's already been taken care of out of the APM funds and you are allocated your sessional rate." (008-APM physician)

- $\quad$ "To be perfectly honest you know, when l'm working in emerg[ency] and someone else prints off on the computer that they've registered, I'm like, ah damn it, I just want to go to sleep. And, if I was actually paid per person and I was knowing that I was getting, you know, the middle of the night rate for seeing someone in emerg, l'd probably be happy because that's me making a ton of money, right? But because I'm salary, I just want to go to bed." (011-APM physician)

Note: $\mathrm{APM}=$ alternative payment model, ARP = alternative relationship plan, $\mathrm{FFS}=$ fee-for-service.

However, there was a recognition that APMs could provide other benefits, including income stability and paid vacation time.

A few physicians noted the potential for perverse incentives under both FFS models and APMs. For APMs, these related primarily to the potential for salary-based models to facilitate practice complacency or a loss of motivation. Indeed, one physician working under an APM described his reduced enthusiasm to see patients during overnight emergency shifts (Box 5). Participants also noted that an FFS model may incent some physicians to see too many patients, which they felt might negatively affect the quality of care. However, physicians who highlighted these concerns felt these issues could be addressed through accountability mechanisms, including regular audits and having clear and appropriate metrics that would benefit patients, physicians and the system as a whole.

\section{Interpretation}

Payment models may have a role to play in mitigating some challenges that physicians face in practising in rural regions, which may influence recruitment or retention. This study identified professional challenges, family-related and personal factors, challenges related to patient care, and community challenges as key determinants in rural physician recruitment and retention in Alberta.

Overall, the physician payment model was not a key factor influencing whether a physician wanted to stay in rural medicine. However, the payment model was perceived to affect (or potentially affect) physicians' experience practising medicine. Specifically, choice of payment model was perceived to affect physician workload (including call burden), patient care, ease of practice and sense of feeling valued. Physicians varied in their preferences toward different models based on their personal values, lifestyle and priorities (e.g., paying off loans, taking holidays or planning for retirement). For study participants, these experiential factors had the greatest influence on physician satisfaction with rural practice.

These findings are consistent with the literature on challenges associated with rural practice ${ }^{1,3,4}$ and emerging literature that shows that physicians' preferences tend to be aligned with nonmonetary incentives associated with payment models. ${ }^{18}$ To leverage payment models to support physician recruitment and retention, it is important to recognize that APMs must be attractive to physicians from the standpoint of nonmonetary incentives noted above.

Results of this study showed that physicians view both FFS models and APMs as having some potential benefits. For instance, physicians noted the potential of APMs to facilitate a collaborative, team-based care model and incorporate creative or innovative methods of delivering medicine (e.g., virtual care) that could create practice and system efficiencies. However, physicians also emphasized the importance of accountability mechanisms to minimize perverse incentives associated with both payment models. These findings are consistent with evidence from other studies on primary care payment models, citing accountability (including metrics) to be a major requirement for successful implementation of payment model reforms. ${ }^{19,20}$

Study participants felt that APMs ought to be developed in collaboration with physicians to account for their knowledge about clinical realities and community peculiarities. They emphasized the importance of physician collaboration and trust in government as key factors to facilitate physician buyin. Building and fostering a positive, trusting and collaborative relationship between physicians and government is an important precondition to facilitate the development of mutually beneficial, customized contracts.

\section{Limitations}

This study involved a small sample, which limits the generalizability of the findings, particularly for physician categories (e.g., gender, age and career stage). Interviews were conducted during the COVID-19 pandemic, which could have influenced the response rate as well as the perspectives and 
responses of physicians who participated in the study. In addition, the ongoing tension between the government and primary care physicians practising in rural and remote areas of Alberta may have biased physicians' responses, particularly regarding payment model changes.

Despite these limitations, factors supporting the credibility of these findings should be noted. Information saturation was achieved after about 8 interviews; however, the researchers continued interviewing beyond saturation to enhance confidence in the findings. In addition, results of this study are consistent with existing literature on factors that facilitate attraction and retention of physicians to rural practice. Specifically, attraction and retention are driven by multiple factors, which include scope and variability of practice, personal or family-related factors, financial incentives and strong physician-patient relationships.

\section{Conclusion}

This study indicates that multiple factors serve to attract and retain primary care physicians to rural practice, including professional challenges, family-related and personal factors, challenges related to patient care, community and physician payment models. Many of these factors are well documented in the literature; however, this research on the role of physician payment models fills an evidence gap given the paucity of evidence in this area.

Although physicians identified a number of benefits of FFS contracts, they also see a space for new and innovative models that may have broad benefits for patients, physicians and the health system as a whole (e.g., improvements in quality of care, patient and provider experience, and potential system-wide cost savings). Factors that influence physicians' experiences are key drivers, and data from this study suggest that physicians are interested in payment models that meet certain criteria around fairness in workload, remuneration and autonomy in practice, and have clear metrics and accountability measures. Considered together, these findings suggest that rural physicians are interested in payment model changes that would make their job easier and incent them to tolerate some of the challenges associated with rural practice. This study indicates that a collaborative, trusting relationship with government, and ability for physicians to have some input and choice in payment models, are key considerations for policy-makers.

\section{References}

1. Soles TL, Ruth Wilson C, Oandasan IF. Family medicine education in rural communities as a health service intervention supporting recruitment and retention of physicians: advancing rural family medicine - The Canadian Collaborative Taskforce. Can Fam Physician 2017;63:32-8.

2. Subedi R, Lawson Greenberg T, Roshanafshar S. Does geography matter in mortality? An analysis of potentially avoidable mortality by remoteness index in Canada. Health Rep 2019;30:3-15.

3. Asghari S, Kirkland MC, Blackmore J, et al. A systematic review of reviews: recruitment and retention of rural family physicians. Can 7 Rural Med 2020; 25:20-30.

4. Cosgrave C, Malatzky C, Gillespie J. Social determinants of rural health workforce retention: a scoping review. Int 7 Environ Res Public Health 2019; $16: 314$.
5. Asghari S, Aubrey-Bassler K, Godwin M, et al. Factors influencing choice to practise in rural and remote communities throughout a physician's career cycle. Can 7 Rural Med 2017;22:92-9.

6. Alternative Relationship Plans (ARP). Government of Alberta. Available: www. alberta.ca/alternative-relationship-plans.aspx (accessed 2020 July 30).

7. Physicians in Canada, 2019. Ottawa: Canadian Institute for Health Information; 2020. Available: www.cihi.ca/sites/default/files/document/physicians-in-canada -report-en.pdf (accessed 2020 Aug. 4).

8. Profiling physicians by payment program: a closer look at three provinces [executive summary]. Analysis in Brief. Ottawa: Canadian Institute for Health Information; 2010. Available: https://secure.cihi.ca/free_products/physicians_payment_ aib_2010_e.pdf (accessed 2020 July 30).

9. Quinn AE, Edwards A, Senior P, et al. The association between payment model and specialist physicians' selection of patients with diabetes: a descriptive study. CMA7 Open 2019;7:E109-16.

10. Quinn AE, Hemmelgarn BR, Tonelli M, et al. Association of specialist physician payment model with visit frequency, quality, and costs of care for people with chronic disease. 7AMA Netw Open 2019;2:e1914861.

11. A case study evaluation: Crowfoot Village Family Practice and the Taber Clinic. Calgary: Health Quality Council of Alberta; 2019. Available: https://hqca.ca/wp -content/uploads/2019/12/HQCA-Crowfoot_Taber-Case-Study-Evaluation -2019.pdf (accessed 2020 July 30).

12. Palys T. Purposive sampling. In: Given LM, editor. The SAGE Encyclopedia of Qualitative Research Methods. Thousand Oaks (CA): SAGE Publications, Inc.; 2008.

13. Saunders B, Sim J, Kingstone T, et al. Saturation in qualitative research: exploring its conceptualization and operationalization. Qual Quant 2018;52: 1893-907.

14. Nowell L, Norris JM, White DE, et al. Thematic analysis: striving to meet the trustworthiness criteria. Int 7 Qual Methods 2017;16. doi: 10.1177/ 1609406917733847.

15. Lincoln YS, Guba EG. But is it rigorous? Trustworthiness and authenticity in naturalistic evaluation. New Dir Program Eval 1986;1986:73-84.

16. Spencer L, Ritchie J. Qualitative data analysis for applied policy research. In: Bryman A, Burges RG, editors. Analysing qualitative data. London (UK): Routledge; 1994:173-94.

17. Gale NK, Heath G, Cameron E, et al. Using the framework method for the analysis of qualitative data in multi-disciplinary health research. BMC Med Res Methodol 2013;13:117.

18. Abelsen B, Olsen JA. Young doctors' preferences for payment systems: the influence of gender and personality traits. Hum Resour Health 2015;13:69.

19. Mukhi S, Barnsley J, Deber RB. Accountability and primary healthcare. Healthc Policy 2014;10:90-8.

20. Health Quality Ontario. A primary care performance measurement framework for Ontario: report of the Steering Committee for the Ontario Primary Care Performance Measurement Initiative - Phase one. Toronto: Queen's Printer for Ontario; 2014. Available: www.hqontario.ca/portals/0/documents/pr/pc-performance -measurement-report-en.pdf (accessed 2020 Aug. 4).

Affiliations: Departments of Community Health Sciences (Ogundeji, Clement, Wellstead, Farkas, Manns) and Medicine (Clement, Manns), University of Calgary, Calgary, Alta.

Contributors: Yewande Ogundeji, Darryn Wellstead, Brenlea Farkas and Braden Manns were responsible for data collection, analysis and interpretation. Yewande Ogundeji, Fiona Clement and Darryn Wellstead drafted the manuscript. All authors were responsible for interpretation of results and critical revision of the manuscript for important intellectual content. All authors gave final approval of the version to be published and agreed to be accountable for all aspects of the work.

Funding: This research was funded by the SPOR Evidence Alliance, with cofunding from a Canadian Institutes of Health Research Foundation Grant.

Content licence: This is an Open Access article distributed in accordance with the terms of the Creative Commons Attribution (CC BY-NC-ND 4.0) licence, which permits use, distribution and reproduction in any medium, provided that the original publication is properly cited, the use is noncommercial (i.e., research or educational use), and no modifications or adaptations are made. See: https://creativecommons.org/licenses/ by-nc-nd/4.0/

Data sharing: All study data are bound by confidentiality agreements and therefore cannot be shared or be available for use by other researchers.

Supplemental information: For reviewer comments and the original submission of this manuscript, please see www.cmajopen.ca/content/9/3/ E788/suppl/DC1. 